\title{
Clinico-demographic Profile of Poisoning Cases Admitted in Intensive Care Unit of Bharatpur Hospital, A Tertiary Referral Center in Nepal \\ Paudyal N, Sapkota K
}

\author{
Department of Internal Medicine \\ Bharatpur Hospital \\ Bharatpur-10, Chitwan, Nepal.
}

\section{Corresponding Author}

Nabin Paudyal

Department of Internal Medicine

Bharatpur Hospital,

Bharatpur-10, Chitwan, Nepal.

E-mail: paudyal.nabin@gmail.com

\section{Citation}

Paudyal N, Sapkota K. Clinico-demographic Profile of Poisoning Cases Admitted in Intensive Care Unit of Bharatpur Hospital, A Tertiary Referral Center in Nepal. Kathmandu Univ Med J. 2020;69(1):54-8.

\section{ABSTRACT}

\section{Background}

Poisoning is a major cause of death in young adults. The epidemiological factors such as geography, occupation, literacy rate can influence the clinical presentation and outcome of the poisoning patients. Poisoning has a significant impact on the economic and social life of individuals.

\section{Objective}

The main objective of this study is an effort to evaluate the characteristic of poisoning cases and identify the reasons for Intensive Care Unit (ICU) admission.

\section{Method}

This was a prospective observational study at Bharatpur Hospital ICU over a period of one year. Demographic profiles, poison characteristics, types and reasons for poisoning, duration of hospital stay, and outcome of the patients were studied.

\section{Result}

A total of 156 patients were admitted with poisoning. Females were affected more than males with a ratio of $\mathrm{F}: \mathrm{M}=1.6: 1$. The age group that consumed poison the most was $16-25$ years, and the mean age group of males was $35 \pm 14$ years and $29 \pm 11$ years respectively. The main cause of poisoning was conflicts/quarrel. Organophosphorus compound was the most common poisoning with $53 \%$ of total cases due to it. There were 07 cases of accidental poisoning secondary to mushroom poisoning. The mean duration of stay in ICU of these patients was 04 days. The total fatality rate due to poisoning was $07 \%$.

\section{Conclusion}

The significant proportion of Intensive Care Unit admission was due to organophosphorus compounds. It was more common among females and young age groups. This calls for special health education on chemical safety among vulnerable people along with efficient supervision in regulatory controls on chemicals and its use.

\section{KEY WORDS}

Conflicts, Intensive care unit, Organophosphorus, Poisoning, Young age 


\section{INTRODUCTION}

Acute poisoning constitutes a significant source of morbidity, mortality, and health care expenditure worldwide. $^{1,2}$ These poisoning could be accidental and intentional poisonings or drug overdoses. Most of the poisoning is due to the intentional self-harm. ${ }^{3}$ Poisoning is a major cause of death in young adults and is a major public health problem. ${ }^{4,5}$ Acute poisoning is a result of intentional or accidental or homicidal ingestion, contact or entry of harmful chemical substances into the body. The toxic effects commonly occur almost immediately, usually within hours from the time of exposure. It is one of the common reasons for visits to emergency departments and for hospitalization. ${ }^{5,6}$ Poison may be absorbed through gastrointestinal route, respiratory route or contact with body surface, in the amounts causing ill effects or death. ${ }^{7}$ The pattern of poisoning varies in different parts depending on a variety of factors such as the availability of different poisons, demography, education, socio-economic status, religious and cultural influences and prescribing habits. ${ }^{8,9}$ The epidemiological factors such as geography, occupation, literacy rate, urgency of management can influence the clinical presentation and outcome of the poisoning patients. ${ }^{10}$

Various studies have identified poisoning as a significant global public health problem. According to WHO data, an estimated 107,000 deaths were caused by unintentional poisonings in 2016 worldwide. Of these deaths, the majority occurred in low and middle income countries. It is estimated that deliberate ingestion of pesticides causes 370,000 deaths each year. It is estimated that some forms of poisons are directly or indirectly responsible for more than 1 million illnesses worldwide annually. ${ }^{2,11}$ The incidence is much higher in the developing and resourcelimited countries.

Few of the studies on epidemiological and clinical profile have been done in Nepal, but most of them are retrospective data on general poisoning. However, little is known about the poisoning profile in intensive care settings in the southern lowland part of central Nepal.

The present study was conducted to characterize acute poisoning cases admitted at ICU of Bharatpur Hospital with regards to demographic factors, common toxic agents used, duration of stay in the ICU and cause for poisoning. All cases of alleged poisoning attending the emergency department of Bharatpur Hospital are triaged based on severity and shifted to the Ward / ICU for further management.

\section{METHODS}

This was a descriptive observational study conducted in the ICU of tertiary referral governmental hospital. The duration of the study period was one year from August 2018 to July 2019 [Fiscal year 2075/2076 BS]. The ethical approval for the study was obtained from the institutional review committee, and an informed consent for the participation in the study was taken from the relatives for each patient. During this study duration, all the cases of suspected acute poisoning admitted to the ICU were included in the study. Any patient who were referred, discharged, left against medical advice or death within $24 \mathrm{~h}$ of ICU admission were excluded from the study. All the patients were first seen and evaluated in the emergency department, brief history and clinical examination performed and life support measures carried out. Patients were then transferred to ICU for further management based on severity. Complete blood counts, urea, creatinine, serum electrolytes, random blood glucose, liver function test and coagulation profile were routinely done for all the patients admitted.

The structured questionnaire consisting of demographic profiles, age, sex, occupation, socioeconomic status, and comorbid conditions were recorded from the patient or patient relatives. The information regarding the poisonous substance or drug included the type of drug, route, intention of poisoning, duration of the first visit to the hospital, total duration of hospital stay, and outcome were analyzed. The type of poison was confirmed from the clinical presentation of the patient, circumstantial evidence, and the remaining container or packets brought by the patient's relatives. All the patients were managed with supportive measures, specific antidotes (if applicable) and system based supportive care based on standard protocol of the hospital.

All the data were recorded and analyzed in IBM SPSS version 21.0, Armonk NY: IBM corp. frequency, distribution, mean, standard deviation was computed. The descriptive statistics are presented as number of cases, percentages and mean.

\section{RESULTS}

During the study period of one year, we had 208 cases of poisoning that were admitted into the ICU. Amongst the admitted cases which 156 were due to chemical poisoning, 109 cases were of snake bite and 2 cases of arthropod sting (bee and Hymenoptera). One case was diagnosed and managed symptomatically as an unknown bite. Poisoning that occurred secondary to ingestion was the major focus of our study.

Of the total 156 cases of poisoning, we found that the female to male ratio was 1.6 (females $=96$, males $=60$ ). Majority of the cases belonged to the $16-25$ years age group (45.8\%), followed by patients belonging to the $26-35$ years age group $(25.0 \%)$ as shown in figure 1 . The mean ages of males and females who consumed poison were $35 \pm 14$ years and $29 \pm 11$ years respectively. 


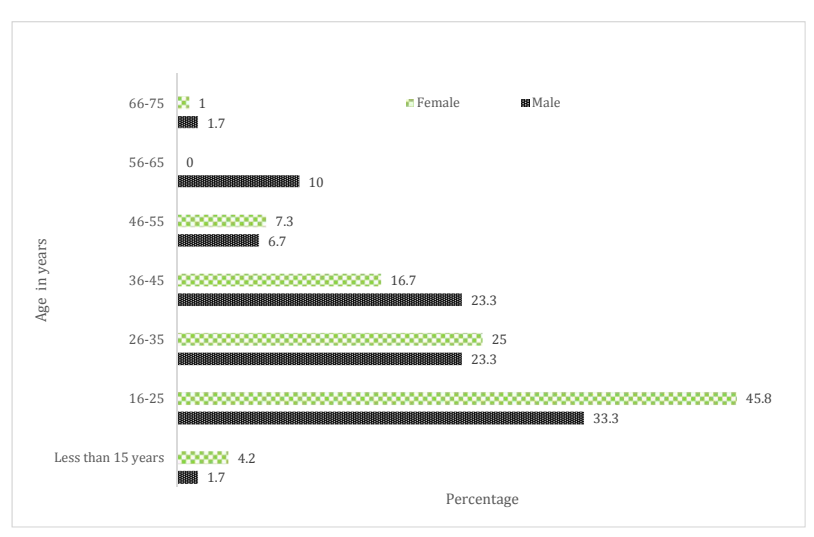

Figure 1. Age-wise distribution of poisoning among cases in the ICU

Poisoning was found to be common among farmers (34.30\%) followed by students (30.8\%). Details about the occupation of people consuming poison are shown in table 1.

Table 1. Showing the occupation of people who consumed poison.

\begin{tabular}{|c|c|c|c|c|}
\hline \multicolumn{5}{|c|}{ Occupation profile } \\
\hline Student & Farmer & Housewife & $\begin{array}{l}\text { Job holder in a } \\
\text { company }\end{array}$ & $\begin{array}{l}\text { Owner of } \\
\text { business }\end{array}$ \\
\hline $30.7 \%$ & $33.9 \%$ & $25.6 \%$ & $8.9 \%$ & $0.6 \%$ \\
\hline
\end{tabular}

One hundred forty-nine cases (95.5\%) were intentional poisoning whereas rest were due to accidental consumption. We found that conflicts/quarrel (including conflicts within the family members and friends) to be the most common cause of intentional poisoning. Major reasons for poisoning are shown in table 2.

Table 2. Showing the causes of poisoning

\begin{tabular}{llll}
$\begin{array}{l}\text { Conflicts/ } \\
\text { Quarrel }\end{array}$ & $\begin{array}{l}\text { Threatening family } \\
\text { members }\end{array}$ & $\begin{array}{l}\text { Financial } \\
\text { cause }\end{array}$ & $\begin{array}{l}\text { Accidental } \\
\text { consumption }\end{array}$ \\
\hline $59.6 \%$ & $21.2 \%$ & $14.7 \%$ & $4.5 \%$
\end{tabular}

We found organophosphorus compounds were mostly misused for self-harm. Other chemicals that were used for poisoning are shown in table 3.

Table 3. Showing the poisons consumed for poisoning.

\begin{tabular}{|ll|}
\hline Types of Poison Consumed & Number of cases (Percentage) \\
\hline Organophosphorus & $83(53.2)$ \\
\hline Organo-carbamates & $13(8.3)$ \\
\hline Zinc/Aluminum Phosphide & $27(17.3)$ \\
\hline Mushroom poisoning & $7(4.5)$ \\
\hline Drug overdose & $4(2.5)$ \\
\hline Chemicals & $11(7.0)$ \\
\hline Unknown compounds & $11(7.0)$ \\
\hline
\end{tabular}

The mean duration of ICU stay was $05 \pm 04$ days with a maximum stay duration of 22 days due to OP poisoning. The overall mortality of the patient due to poisoning was $07 \%(n=11)$. Organophosphorus poisoning was responsible for the greatest number of deaths (45.5\%), followed by mushroom poisoning (18.2\%) and Aluminum phosphide poisoning (18.2\%).

\section{DISCUSSION}

Acute poisoning remains a public health problem with significant morbidity and mortality and is one of the major causes for emergency visit and hospital admission. ${ }^{5}$ Prompt diagnosis and appropriate management is crucial for better clinical outcome.

In this study, the ratio of female cases was higher (61.5\%) than males. Various studies within Nepal have reported similar female predominance in poisoning cases. ${ }^{12,13}$ Females are more vulnerable for suicidal attempts and poisoning than the males in developing countries due to increased risk of domestic physical and sexual violence, problematic marital relationship, lack of emotional support, economic and social hardship. ${ }^{13,14}$ Since all patients with poisoning that were admitted to the ICU at Bharatpur Hospital are only the study population, the actual gender ratio might differ when all the patients that are admitted to emergency care are included.

Most of the poisoning were from the age group 16-25 years. Similar incidence in the young age group was reported in various studies. ${ }^{10,15-17}$ This young age of presentation could be due to the dynamic nature and role of this age group, and pressure from family, peers, society, workplace and various role conflicts. ${ }^{10,13,15,18,19}$ Factors associated with increased stress like family conflict, peer pressure, personal and social responsibilities, conflict with in-laws, unemployment etc. provides an individual with negative thought and perception towards self and inability to cope with these life stressors, pushes himself to extreme measures like suicide.

Almost all cases of poisoning were due to suicidal intention (95.5\%) and impulsive act being the most common. Similar findings were reported in other studies. ${ }^{10,16,17}$ It was a direct result of conflict and impulsive act since the majority of the patients were from a young age group. We did not find any strong risk factors or underlying cause for self poisoning for which it would be easy to suggest interventions. It is likely that combination of factors like unemployment, broken relationships, domestic violence could have played role with acute stressful events, which led to an eventual suicide attempt. Pesticides are the easiest method for self harm in agricultural societies in developing countries, the high incidence of self harm translates into high numbers of severe acute pesticide poisoning. ${ }^{18}$

The most common cause for poisoning was due to organophosphorus compounds. People with farming (agriculture) as their main occupation mostly use this compound. Easy availability of these compounds in their community, keeping of the pesticides within close proximity to the household may be the reason why these compounds have such a high incidence of misuse. ${ }^{20}$ Studies 
done across different centers in developing countries also describe similar findings reflecting a huge burden of the problem. ${ }^{12,21}$ The ease of availability of such lethal means of self-harm may influence patterns of suicide. Suicidal impulses are often short lived, and these acts are unplanned, the methods used are those that are readily available at the time of acute distress. ${ }^{14}$ A proportion of suicides will be prevented if time can be 'bought' allowing such impulses to pass by making the means of suicide less readily available. ${ }^{22}$ All accidental poisoning occurred due to consumption of poisonous Mushroom (4.5\%). People, especially in the suburban/rural area used wild mushrooms as an option for vegetables. Consumption of these mushrooms occurred due to ignorance of these patients rather than as a recreation or an attempt of self harm. This is consistent with other studies carried out in Nepal. ${ }^{13}$ Farmers and agricultural workers face chronic health effects from chronic exposure to pesticides. ${ }^{23}$ Farmers can have minor symptoms due to occupational pesticides exposure and they may not generally seek medical consultation and the milder cases that do seek care at health facilities often go unrecognized because the symptoms are similar to other health conditions. ${ }^{24-26}$ However, in case of suicidal use of pesticides and accidental exposure, close relatives seek early emergency medical services; even if the ingested dose of pesticide is not fatal. This could be the reason for an increased number of cases of suicidal ingestion in this study.

The mean duration of stay of all poisoned patients in our ICU was $05 \pm 04$ days, and mean duration of stay of patients with OP was 07 days. The duration of ICU stay was longer in patients with organophosphorus poisoning. The longer duration required for patients to recover, longer duration of antidote and mechanical ventilation in organophosphorus poisoning as observed in the study might have contributed to a longer duration of ICU stay. Pulmonary complications such as increased secretion, pneumonia and respiratory paralysis are frequently seen in patients with organophosphorus poisoning which leads to longer duration of stay in ICU. ${ }^{10,27}$

As Bharatpur Hospital is a government hospital with majority of patients from low socio economic status, any prolonged duration of stay adds economic burden to such patients. In a span of 1 year, we had overall mortality of $7 \%$ due to poisoning. Late arrival to the hospital, chemical nature of the poison ingested and cardio respiratory complications due to poisoning are the most important factors responsible for mortality in such patients.

This study only focused on the profiles of chemical poisoning, other causes for poisoning and other means of intentional self-harm were not known. Since this was a single center hospital based study and only enrolled the serious cases of poisoning admitted to intensive care units, the actual scenario in milder cases who were treated in general wards could be different, and this may be considered as the limitation of the study.

\section{CONCLUSION}

Acute poisoning in any form is a medical emergency that requires prompt admission and management in the ICU. Early identification of the poison, rapid resuscitation with standard management and continuous observation of the patients can reduce the complication and mortality due to poisoning. Poisoning as a disease affects all age groups however, poisoning by the people of a productive age group after conflict or as a tool to threaten family members for attention is concerning. Until the compounds like organophosphorus are easily available to the public, targets in reducing overall incidence of deliberate self-harm cannot be achieved. Single poisoning attempt by patients creates economic and psychological burden to themselves and their family members. Hence, implementation of strict regulations and rules in marketing of these poisonous compounds need to be done. To reduce the incidence of poisoning in young age groups, awareness programs in schools, colleges and communities are required. Timely consultation with medical personnel and mental health professionals will help minimize the risk of next attempt in deliberate self-harm. Establishment of separate wards for poison patients, implementation of guidelines / criteria for ICU admission of poisoned patients will help reduce unnecessary admission of patients in the Intensive Care Unit and reduce unnecessary cost burden to the patient.

\section{REFERENCES}

1. Gummin DD, Mowry JB, Spyker DA, Brooks DE, Beuhler MC, Rivers LJ, et al. 2018 Annual Report of the American Association of Poison Control Centers' National Poison Data System (NPDS): $36^{\text {th }}$ Annual Report. Clin Toxicol. 2019;57(12):1220-413.

2. World Health Organisation: Poisoning Prevention and Management. [cited 2020 Sep 5]. Available from: https://www.who.int/ipcs/ poisons/en/

3. Konradsen F, Dawson AH, Eddleston M, Gunnell D. Pesticide selfpoisoning: thinking outside the box. Lancet. 2007;369(9557):169-70.

4. Ralston SH, D PI, Strachan MWJ, Hobson R, editors. Davidson's Principles and Practice of Medicine. 23 ${ }^{\text {rd }}$ ed. Elsevier; 2018. 134 p.

5. Kondrasen F. Acute pesticide poisoning. Dan Med Bull. 2007;54(1): 58-9.

6. Eddleston M. Patterns and problems of deliberate self-poisoning in the developing world. QJM - Mon J Assoc Physicians. 2000;93(11):715-31.

7. Ayog F. Etiological and demographical characteristics of acute adult poisoning in Ankara, Turkey. 1999;(August):401-6.

8. Senanayake $\mathrm{N}$, Peiris $\mathrm{H}$. Mortality due to poisoning in a developing agricultural country: Trends over 20 years. Hum Exp Toxicol. 1995;14(10):808-11.

9. WHO. The global burden of disease 2004. Updat World Heal Organ $2004 ; 146$. 
10. Rajbanshi LK, Arjyal B, Mandal R. Clinical Profile and Outcome of Patients with Acute Poisoning Admitted in Intensive Care Unit of Tertiary Care Center in Eastern Nepal. Indian J Crit Care Med. 2018;22(10):691-6.

11. World health statistics:2019: monitoring health for the SGDs, Sustainable Development Goals. Geneva: World Health Organization 2019 https://apps.who.int/iris/bitstream/hand le/10665/324835/9789241565707-eng.pdf?ua=1

12. Gupta SK, Joshi MP. Pesticide poisoning cases attending five major hospitals of Nepal. J Nepal Med Assoc. 2002;41(144):447-56.

13. Gyenwali D, Vaidya A, Tiwari S, Khatiwada P, Lamsal DR, Giri S. Pesticide poisoning in Chitwan, Nepal: A descriptive epidemiological study. BMC Public Health. 2017;17(1):1-8.

14. Gunnell DJ, Eddleston M. Suicide by intentional ingestion of pesticides: A continuing tragedy in developing countries. Int $J$ Epidemiol. 2003;32(6):902-9.

15. Sharma R, Neelanjana, Rawat N, Panwar N. Mortality and morbidity associated with acute poisoning cases in north-east India: A retrospective study. J Fam Med Prim Care. 2019;8(6):2068-72.

16. Mehrpour et al. reference: Mehrpour O, Akbari A, Jahani F, Amirabadizadeh A, Allahyari, Mansouri B. Epidemiological and clinical profiles of acute poisoning in patients admitted to the intensive care unit in eastern Iran (2010 to 2017). BMC Emerg Med. 2018;18(1):30.

17. Sulaj Z, Prifti E, Demiraj A, Strakosha A. Early Clinical Outcome of Acute Poisoning Cases Treated in Intensive Care Unit. Med Arch. 2015;69(6):400.

18. Van Der Hoek W, Konradsen F. Risk factors for acute pesticide poisoning in Sri Lanka. Trop Med Int Heal. 2005;10(6):589-96.
19. Konradsen F, Hoek W Van Der, Peiris P. Reaching for the bottle of pesticide - A cry for help. Self-inflicted poisonings in Sri Lanka. Soc Sci Med. 2006;62(7):1710-9.

20. Gunnell D, Eddleston M, Phillips MR, Konradsen F. The global distribution of fatal pesticide self-poisoning: Systematic review. BMC Public Health. 2007;7(c):1-15.

21. Banerjee I, Tripathi SK, Roy AS, Sengupta P. Pesticide use pattern among farmers in a rural district of West Bengal, India. J Nat Sci Biol Med. 2014;5(2):313-6.

22. Clarke R, Lester V. Suicide: Closing the Exits. In New York: SpringerVerlag; 1989. p. 85-95.

23. Antle JM, Pingali PL. Pesticides, Productivity, and Farmer Health: A Philippine Case Study. Am J Agric Econ. 1994;76(3):418-30.

24. United States General Accounting Office. Pesticides on farms Limited capability exists to monitor occupational illness and injuries. Washington, D.C: U.S. General Accounting Office; 1993.

25. Ncube NM, Fogo C, Bessler P, Jolly CM, Jolly PE. Factors associated with self-reported symptoms of acute pesticide poisoning among farmers in Northwestern Jamaica. Arch Environ Occup Heal. 2011;66(2):65-74.

26. Jors E, Morant R, Aguilar G, Hulci O, Lander F, Baelum J, et al. Occupational pesticide intoxications among farmers in Bolivia: a cross-sectional study. Env Heal. 2006;5(10).

27. Giyanwani PR, Zubair U, Salam O, Zubair Z. Respiratory Failure Following Organophosphate Poisoning: A Literature Review. Cureus. 2017;9(9):3-9. 